\title{
Development Model of Elderly Health Care Behavior with Public Mind
}

\author{
Jarun Jukravalchaisri \\ Expert Public Health Officer \\ Bureau of Technical Advisor \\ Department of Health, Ministry of Public Health, Thailand \\ Email:jj112450@gmail.com \\ Kessanee Koktatong \\ Senior Public Health Officer \\ Regional Health Promotion Center 4, Thailand \\ Email:koktatong@gmail.com \\ Utaiwan Koktatong \\ Public Health Office \\ Regional Health Promotion Center 4, Thailand \\ Email: fcrb@windowslive.com
}

\section{Doi:10.5901/mjss.2013.v4n6p141}

\section{Abstract}

In order to promote the elderly peoples to have high competency for self heal care and take care other old person with public mind, it needs to understand factors that is affecting to their health behavior. Therefore, the study on elderly health care knowledge, supportive factor, psychological factors and inspiration of public mind will make us more understand the way the elderly people not just only look after themselves but they also are able to assist to help the other elderly people. Moreover, this finding will be useful for our global old citizen to meet the better life quality. The objective was to develop the structural relationship model of elderly health care knowledge, psychological trait, psychological state, and social support affecting through inspiration of public mind to health behavior. The populations were 125,037 elderly peoples in Ratchaburi Province in the year of B.E. 2556. The sample group of 400 elderly peoples were sampling with Multi-stage random sampling technique. Questionnaire was used as research tool that was examined for content validity by 5 experts and it was tried out with the group that was not sample group. The reliability in aspects of elderly health care knowledge, psychological trait, psychological state, supportive factor, inspiration of public mind and health behavior were $0.898,0.855,0.878,0.899,0.919$ and 0.920 respectively. Analysis of causal relationship model was verified with Structural Equation Model (SEM) by using LISREL version 8.72. The results revealed that the developed structural equation model of elderly health care behavior with public mind of elderly people in Ratchaburi Province was congruent to empirical data by considering on the values of $\chi^{2} / d f=1.609$ was lesser than 5, RMSEA = 0.043 (<0.05), GFI=0.94 (0.90-1.00), AGFI=0.91 (0.90-1.00), RMR=0.010 (<0.05). Model composed of 29 observed variables, and 6 latent variables. All factors positively affected to health behavior and were able to explain the variation of health behavior $(\mathrm{HB})$ with 86.00 percents. The latent variable of elderly health care knowledge (EHK) had the most effect to health behavior (HB) with 0.44 , and subsequences were inspiration of public mind (IPM), supportive factor (SuF), psychological state (PSS), and psychological trait (PST) with 0.34, 0.34, 0.25 and 0.19 respectively. Moreover, the latent variable psychological trait (PST) had the most effect to inspiration of public mind (IPM) with 0.50 , and subsequences were psychological state (PSS), supportive factor (SuF), and elderly health care knowledge (EHK) with $0.41,0.34$ and 0.084 respectively.

Keywords: Development Model / Elderly Health Care Behavior / Public Mind

\section{Introduction}

The population of Thailand is getting old. At the present time, just less than $11.00 \%$ of the Thai population is over 60 years of age and the trend is rapidly rising. The proportion of old persons in the total population is expected to reach $14 \%$ in 2015, 19.8\% in 2025 and nearly 30\% in 2050, because Thailand's success story is a cause for celebration of more 
children surviving childhood and more women surviving childbirth but also getting more control over their fertility. Therefore, Thailand's ageing population also represents an enormous challenges (Population Division, Department of Economic and Social Affairs (DESA), United Nations, 2001; Office of National Statistic, 2012; Maranet, 2012).

The decreased birth rates and ageing populations increased are main issues for high-income countries, as the United Nations report points out, this demographic shift is now being felt most acutely in developing countries, particularly in Asia, where more than half of the world's over 60 years old with 400 millions presently reside. Currently, the demographic alterations being experienced by low- and middle-income countries are happening much more quickly than was the case for Europe and North America. However, a number of Asian countries, including China, Indonesia, Japan, Myanmar, the Republic of Korea, Singapore, Thailand and Viet Nam have fertility rates drop below the total fertility rates close to or below the level needed to replace their populations. Consequently, younger people and, in particular, younger relatives in Thailand are the most ordinary source of income for the older people, and expectations of filial support in old age and are shared commonly by the current generation of adults (WHO, 2012; Ratanatikul, et al., 2012; Population Division, Department of Economic and Social Affairs (DESA), United Nations, 2001; Office of National Statistic, 2012).

Even though, Thai government has taken a number of steps at the national level to direct more resources into supporting older people, including the launch of a National Pension Fund in March 2011. The hope is that the expansion of the retirement pension among insured workers under the social security system and savers under a planned National Savings Scheme will be enough to counterbalance the likely loss of filial support. Judging by the experience of other countries, such schemes alone may not be adequate. However, the empowerment to elderly who are strong and health for self heal care and support other with public mind, might be important issue for consideration (WHO, 2012; Thiengkamol, 2002a, Thiengkamol, 2009b, Thiengkamol, 2011f).

Conversely, not all elderly people is a person who is burden of family and social but for the one who is still active and knowledgeable people because they gain a lot of worth knowledge and valuable experiences. Therefore they can assist the other old persons and family to look after their grand children and give precious recommendations for next generations (Chansirakanjana, 2009; Wechwitan, 2008).

Elderly health care knowledge included elderly physical health knowledge, elderly general disease knowledge, elderly specific health knowledge, elderly mental health knowledge and elderly health risk knowledge are very crucial issues to maintain old person to have a better life quality. Moreover, when the old persons have good physical and mental health together with knowledge to practice in daily life to prevent both infectious and non-infection disease including avoid to take risk behavior such as smoking, alcohol drinking and caring for accident occurrence (Phinnarach, et al, 2012a; Artwanichakul,2012a).

In addition, psychological factors of psychological trait and state cannot be omitted because the action or practice of individual is stimulate or inspire by any stimulants of person, event, environment or media, therefore in order to better understand the pattern of human behavior, the psychological trait and state should be introduced in this study. The very well known theory of psychology as worldwide used at present is in Interactionism model that developed by Magnusson and Endler, traduced in the book named "Personality at the crossroads" that compiled the theories of human behavior on integration of mind and states together (Punthumnavin, 2008; Magnusson, \& Endler, 1997; Magnusson, 1999; Magnusson, 2001). This assists the study to considering on the causes of behavioral expression in diverse dimensions such as cause of mind, cause states, and cause of co-influence or interaction between characteristics of mind and state of actor. The holistic interactionist paradigm presents a vision where individual characteristics are likely to be inconsistent (Cervone, 1991; Magnusson, 2001; Pervin, 1999; Pervin, 2001; Cairns, 2001). In a given condition the action of a individual is a procedure of integration and composite adjustment of which the components: brain, insight and cognition (counting involuntary processes), sentiments and values, physiological structure, and behavior interact among each other and in a practical way with the environment. Beside physical and social aspects of situations, especially they are close and are interpreted by the individual and express adjustable responses (Cairns, 1979; Magnusson, 1999). The complexity of expression implies that the operation of the individual or organization cannot be explained by only one factor of trait from genetic or natural environment (Susman 2001; Thiengkamol, 2101f). A certain number of principles apply to individual development such as those of multi-determination, equi-potentiality and equi-finality of level (Pervin, 1999; Zuckerman, 1998; Pervin, 2001), or of linear transformation and synchronization (Magnusson, 2001). Recently, Thiengkamol and colleagues, studied on the psychological trait and state included self-confident, mercy and kindness, achievement motive, locus of control, self-value of living, attitude toward sufficiency, and faithful to religion, and familyvalue of living (Thiengkamol, 2011i; Thiengkamol, 2011; Thiengkamol, 2012c; Thiengkamol, 2012d; Donkonchum, and Thiengkamol, 2012; Thiengkamol, 2012e, Thiengkamol, 2012f; Thiengkamol, 2012h; Waewthaisong, et al., 2012a; Udonboon, et a., 2012b). 
Supportive factors for elderly health care accomplishment, there are various variables such as family support, community support, social support, and religion support and so on. The different studied revealed that the role and function of Thai family they are generally malfunction with only 8.80 percent and most of them are still tight-knit family or warm hearted family to look after each other, even elderly people. However, Thailand regarded to the rapid change of economic pattern from traditional style to be materialism or capitalism, hence it causes alteration of demography, economic, social and tradition including behavior, belief and attitude variations as well. Even though in aboard, the issue of homeless people or practice of parents with gay child are seriously problems of the old person (Chamrasritwomg \& Chulert, 2009; Phothisita \& Tawesit, 2009; Knodel, \& Chayovan, 2009). Nevertheless, the family caregiver should not omit to understand their satisfaction as well (Ekwall, \& Hallberg, 2007).

Besides family is an origin of elderly support, the effective social support system is a very significant factor for some elderly who is homeless or stand alone (Kelly, et al., 2008).

The numerous studies pointed out that the social include both government and private sector play very important role to look after them. Particularly community support is a close agent to elderly people, therefore the old person might be looked after by community, it will be more appropriate and convenient (Srithamrongsawat, et al., 2009; Flanagan, 1996; Horner, \& Boldy, 2008; Minkler, et al., 2008; Nocon, \& Pearson, 2000).

Even though the family is a primary organization to support elderly health care because it needs long term care (Koff, 1982), therefore, social or social network support is also required for physical and mental care for old person. Especially for releasing the stress and anxiety of elderly people, thus, there are different center elderly with both full time and day time in western countries but Thai culture based on Buddhist region, it beliefs that the son, daughter and grand children do have the duty to pay respect and look after with gratitude (Yodpetch, S, 2009; Heaney, \& Israel, 1997; Hooyman, \& Kiyak, 2009; Horner, \& Boldy, 2008; Kespichayawattana, \& Jitapunkul, 2009; Knodel, \& Chayovan, 2008; Minkler, et al., 2008; Montgomery, \& Kwak, 2008; Nocon, \& Pearson, 2000; Neufeld, \& Harrison, 2010; O'Shea, 2002; Saunder, 2006; Toseland,et al., 2007).

Inspiration of public consciousness or public mind was proposed by Thiengkamol (2009a, 2009b; 2011e; 2011f) that inspiration is completely disparate from motivation because one who do or act or practice with the drive from inside with desire to do for public, especially, for other people or environmental conservation. However, this might be happened from the intuition of good role model of person, event, environment and various media that inspire him/her to do for others or public without the required of rewards, money, respect or appreciation but one feels pleasurable to make for others or public (Thiengkamol, 2009a; Thiengkamol, 2009b; Thiengkamol, 2011e; Thiengkamol, 2011f; Thiengkamol, 2011;; Thiengkamol, 2012e; Thiengkamol, 2012f; Thiengkamol, 2012h; Donkonchum, \& Thiengkamol, 2012; Donkonchum, et al., 2012a; Waewthaisong, et al, 2012a; Gonggool, et al., 2012b; Morrasri, et al., 2012b).

Therefore, developing the causal relationship model of elderly health care behavior with public mind, it should consider elderly health care knowledge, psychological trait, psychological state and social support that affected through inspiration of public mind to cause health behavior.

\section{Objective}

The objective was to develop the structural relationship model of elderly health care knowledge, psychological trait, psychological state, and social support affecting through inspiration of public mind to health behavior.

\section{Methodology}

The research design was implemented in steps by step as follows:

1. The populations were 125,037 elderly peoples in Ratchaburi Province in the year of B.E. 2556. The Multistage random sampling was employed to collect 400 elderly peoples from different villages of Ratchaburi Province.

2. The research instrument was the questionnaire and it was used for data collecting. The questionnaire composed of 210 questions with 5 rating scales. Structural Equation Model (SEM) was used for model verification by using LISREL version 8.72 . The content and structural validity were determined by Item Objective Congruent $(\mathrm{IOC})$ with 5 experts in the aspects of elderly health care, psychology, social science and social research methodology. The reliability was done by collecting the sample group from 40 elderly peoples who were not sample group. The reliability was determined by Cronbach's Alpha. The reliability in aspects of 
elderly health care knowledge, psychological trait, psychological state, supportive factor, inspiration of public mind and health behavior were $0.898,0.855,0.878,0.899,0.919$ and 0.920 respectively.

3. The descriptive statistics used were frequency, percentage, mean and standard deviation. Structural Equation Model (SEM) was used for model verification by using LISREL version 8.72 with considering on Chi-Square value differs from zero with no statistical significant at 0.05 level or Chi-Square/df value with lesser or equal to 5, P-value with no statistical significant at 0.05 level and RMSEA (Root Mean Square Error Approximation) value with lesser than 0.05 including index level of model congruent value, GFI (Goodness of Fit Index) and index level of model congruent value, AGFI (Adjust Goodness of Fit Index) between 0.90-1.00.

\section{Results}

\subsection{General Characteristics of Sample Group}

The sample group was 400 elderly peoples that were selected by Multi-stage random sampling technique from different villages of Ratchaburi Province in the year of B.E. 2556. The results showed that most of them were female with 224 peoples $(56.00 \%)$, most of them had married status with 316 peoples $(79.00 \%)$, and graduated at primary education level with 149 peoples (37.25\%). Majority were house works with 131 peoples (32.75\%), and had average age with 64.73 years as presented in table 1 .

Table 1 General Characteristics of Sample Group of Elderly People

\begin{tabular}{|c|c|c|c|}
\hline \multirow{2}{*}{\multicolumn{2}{|c|}{ General Characteristics }} & \multicolumn{2}{|c|}{ Elderly People } \\
\hline & & Frequent & Percents \\
\hline \multirow[t]{2}{*}{ Sex } & Male & 176 & 44.00 \\
\hline & Female & 224 & 56.00 \\
\hline \multirow[t]{3}{*}{ Marital Status } & Single & 19 & 4.75 \\
\hline & Married & 316 & 79.00 \\
\hline & Separated/Widow/Divorce & 65 & 16.25 \\
\hline \multicolumn{4}{|c|}{ Educational Level } \\
\hline & Primary & 149 & 37.25 \\
\hline & Lower Secondary & 54 & 13.50 \\
\hline & Upper Secondary Nocational & 99 & 24.75 \\
\hline & Higher Vocational /Diploma & 19 & 4.75 \\
\hline & Bachelor & 65 & 16.25 \\
\hline & Higher than Bachelor & 14 & 3.50 \\
\hline \multicolumn{4}{|c|}{ Main Occupation } \\
\hline & House Work & 131 & 32.75 \\
\hline & Government retired/State Enterprise retired & 108 & 27.00 \\
\hline & Merchant/ Business owner & 63 & 15.75 \\
\hline & General hire & 28 & 7.00 \\
\hline & Agriculturist & 70 & 17.50 \\
\hline Age & Average age $=64.73$ years & \multirow{2}{*}{\multicolumn{2}{|c|}{$\begin{array}{l}\text { Maximum }=89 \text { years } \\
\text { Minimum }=61 \text { years }\end{array}$}} \\
\hline & Standard deviation=4.099 & & \\
\hline \multicolumn{2}{|l|}{ Total } & 400 & 100.00 \\
\hline
\end{tabular}

\subsection{Results of Confirmatory factors Analysis of Exogenous Variables}

\subsubsection{Confirmatory Factors Analysis of Exogenous Variables of Elderly Health Care Knowledge (EHK)}

Confirmatory Factor Analysis of Exogenous Variables of Elderly Health Care Knowledge (EHK) affecting Health Behavior $(\mathrm{HB})$ was revealed as the followings.

Confirmatory factors of EHK had Bartlett's test of Sphericity of 696.050 statistically significant level of 0.01 , and Kaiser-Mayer-Olkin Measure of Sampling Adequacy/MSA of 0.777. This indicated that components of EHK aspect had proper relationship at good level and it can be used for analysis of confirmatory factors as shown in picture 1 and table 2 . 


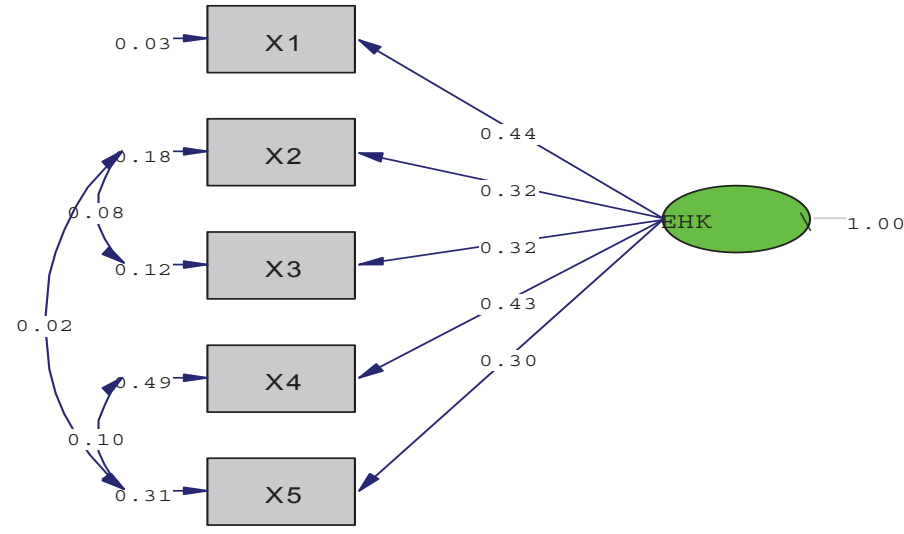

Chi-Square=2.41, df=2, P-value=0.29999, RMSEA=0.023

Picture 1: Results of Analysis of Confirmatory factors of EHK

Table 2. Results of Analysis of Confirmatory Factors of EHK

\begin{tabular}{|c|c|c|c|c|}
\hline Components of EHK & Weight & SE & $t$ & $R^{2}$ \\
\hline X1 Elderly physical health knowledge & 0.44 & 0.025 & $17.19^{\star \star}$ & 0.86 \\
\hline X2 Elderly general disease knowledge & 0.32 & 0.029 & $11.18^{\star \star}$ & 0.36 \\
\hline X3 Elderly specific health knowledge & 0.32 & 0.025 & $12.85^{\star \star}$ & 0.47 \\
\hline X4 Elderly mental health knowledge & 0.43 & 0.044 & $9.90^{\star \star}$ & 0.28 \\
\hline X5 Elderly health risk knowledge & 0.30 & 0.034 & $8.87^{\star \star}$ & 0.23 \\
\hline \multicolumn{5}{|c|}{$\begin{array}{lll}\text { Chi-square }=2.41 & \mathrm{df}=2 & P=0.29999\end{array}$} \\
\hline $\mathrm{GFI}=1.00 \quad \mathrm{AGFI}=0.98$ & RMSEA $=0.023$ & RMR & & \\
\hline
\end{tabular}

** Statistically significant level of 0.01

From picture 1 and table 2, results of analysis of confirmatory factors of EHK from 5 observed variables was revealed that the model was congruent to empirical data by considering from 1) Goodness of Fit Index (GFI) equaled to 1.00 and Adjust Goodness of Fit Index (AGFI) equaled to 0.98, 2) Root Mean Square Error of Approximation (RMSEA) equaled to 0.000 (RMSEA < 0.05), and 3) Chi- Square value had no statistically significant at level of 0.01 and divided by degree of freedom was lesser than or equaled to $5\left(\chi^{2} / \mathrm{df} \leq 5.00 \quad\right.$ ).

Considering on loading weight of 5 observed variables in model, it was revealed that observed variables had loading weight with 0.30 to 0.44 and had covariate to model of EHK with 23.00 to 86.00 percents.

\subsection{Confirmatory Factors Analysis of Exogenous Variables of Psychological Trait (PsT)}

Confirmatory Factor Analysis of Exogenous Variables of Psychological Trait (PsT) affecting to Health Behavior (HB) was revealed as the followings.

Confirmatory factors of PST had Bartlett's test of Sphericity of 652.157 statistically significant level of 0.01 , and Kaiser-Mayer-Olkin Measure of Sampling Adequacy/MSA of 0.817. This indicated that components of PsT aspect had proper relationship at good level and it can be used for analysis of confirmatory factors as shown in picture 2 and table 3 . 


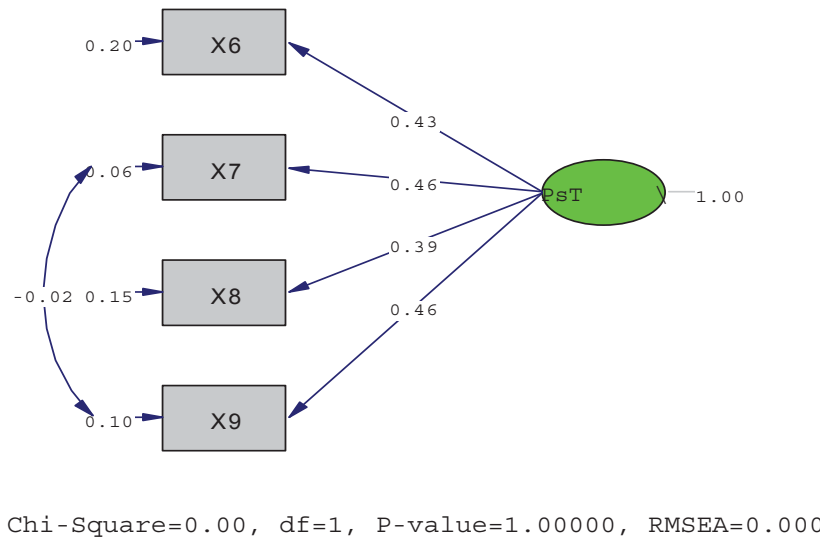

Picture 2: Results of Analysis of Confirmatory factors of Psychological Trait

Table 3 Results of Analysis of Confirmatory Factors of Psychological Trait

\begin{tabular}{l|l|l|l|l}
\hline \hline Components of Psychological Trait & Weight & SE & $\mathrm{t}$ & $R^{2}$ \\
\hline X6 Self-confidence & 0.43 & 0.031 & $14.07^{\star \star}$ & 0.48 \\
X7 Mercy and Kindness & 0.46 & 0.026 & $17.86^{\star \star}$ & 0.78 \\
X8 Achievement motive & 0.39 & 0.027 & $14.48^{\star \star}$ & 0.51 \\
X9 Locus of control & 0.46 & 0.029 & $16.02^{\star \star}$ & 0.68 \\
\hline Chi-square $=0.00 \quad \mathrm{df}=1 \quad \mathrm{P}=1.0000$ \\
GFI = 1.00 AGFI =0.99 RMSEA =0.000 RMR =0.0020
\end{tabular}

** Statistically significant level of 0.01

From picture 2 and table 3, results of analysis of confirmatory factors of PsT from 4 observed variables was revealed that the model was congruent to empirical data by considering from 1) Goodness of Fit Index (GFI) equaled to 1.00 and Adjust Goodness of Fit Index (AGFI) equaled to 0.99,2) Root Mean Square Error of Approximation (RMSEA) equaled to 0.000 (RMSEA < 0.05), and 3) Chi- Square value had no statistically significant at level of 0.01 and divided by degree of freedom was lesser than or equaled to $5.00\left(\chi^{2} / \mathrm{df} \leq 5.00 \quad\right)$.

Considering on loading weight of 4 observed variables in model, it was revealed that observed variables had loading weight with 0.39 to 0.46 and had covariate to model of PST with 48.00 to 78.00 percents.

\subsection{Confirmatory Factors Analysis of Exogenous Variables of Psychological State (PsS)}

Confirmatory Factor Analysis of Exogenous Variables of Psychological State (PsS) affecting to Health Behavior (HB) was revealed as the followings.

Confirmatory factors of PsS had Bartlett's test of Sphericity of 704.483 statistically significant level of 0.01 , and Kaiser-Mayer-Olkin Measure of Sampling Adequacy/MSA of 0.755. This indicated that components of PsS aspect had proper relationship at good level and it can be used for analysis of confirmatory factors as shown in picture 3 and table 4 . 


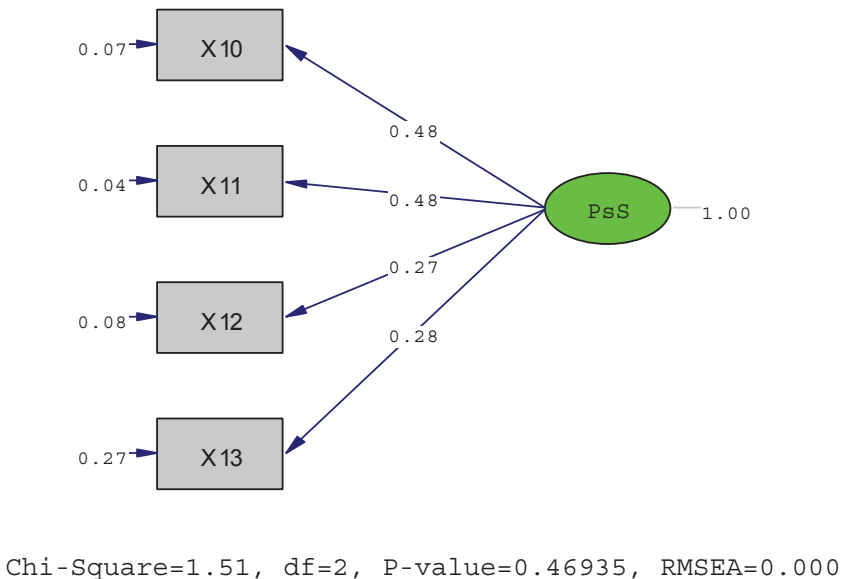

Picture 3: Results of Analysis of Confirmatory factors of Psychological State

Table 4. Results of Analysis of Confirmatory factors of Psychological State

\begin{tabular}{l|c|c|c|c}
\hline \hline Components of Psychological State & Weight & SE & $\mathbf{t}$ & $R^{2}$ \\
\hline X10 Self-value living & 0.48 & 0.02 & $20.45^{\star *}$ & 0.78 \\
X11 Attitude toward sufficiency & 0.48 & 0.02 & $21.60^{\star *}$ & 0.84 \\
X12 Religion belief & 0.27 & 0.02 & $14.91^{\star *}$ & 0.49 \\
X13 Family-value living & 0.28 & 0.03 & $9.19^{\star *}$ & 0.22 \\
\hline Chi-square $=1.51 \quad \mathrm{df}=2$ \\
GFI $=1.00 \quad \mathrm{AGFI}=0.99 \quad$ RMSEA $=0.000 \quad$ RMR $=0.0026$ \\
\hline
\end{tabular}

** Statistically significant level of .01

From picture 3 and table 4, results of analysis of confirmatory factors of PsS from 5 observed variables was revealed that the model was congruent to empirical data by considering from 1) Goodness of Fit Index (GFI) equaled to 1.00 and Adjust Goodness of Fit Index (AGFI) equaled to 0.99, 2) Root Mean Square Error of Approximation (RMSEA) equaled to 0.000 (RMSEA < 0.05) and 3) Chi- Square value had no statistically significant at level of 0.01 and divided by degree of freedom was lesser than or equaled to $5.00\left(\chi^{2} / \mathrm{df} \leq 5.00 \quad\right)$.

Considering on loading weight of observed variables in model, it was revealed that observed variables had loading weight with 0.27 to 0.48 and had covariate to model of PsS with 22.00 to 84.00 percents.

\subsection{Confirmatory factors Analysis of Exogenous Variables of Supportive Factor (SuF)}

Confirmatory Factor Analysis of Exogenous Variables of Supportive Factor (SuF) affecting to Health Behavior (HB) was revealed as the followings.

Confirmatory factors of SuF had Bartlett's test of Sphericity of 1450.358 statistically significant level $(p<0.01)$ and Kaiser-Mayer-Olkin Measure of Sampling Adequacy/MSA) of 0.750. This indicated that components of SuF aspect had proper relationship at good level and it can be used for analysis of confirmatory factors as shown in picture 4 and table 5. 


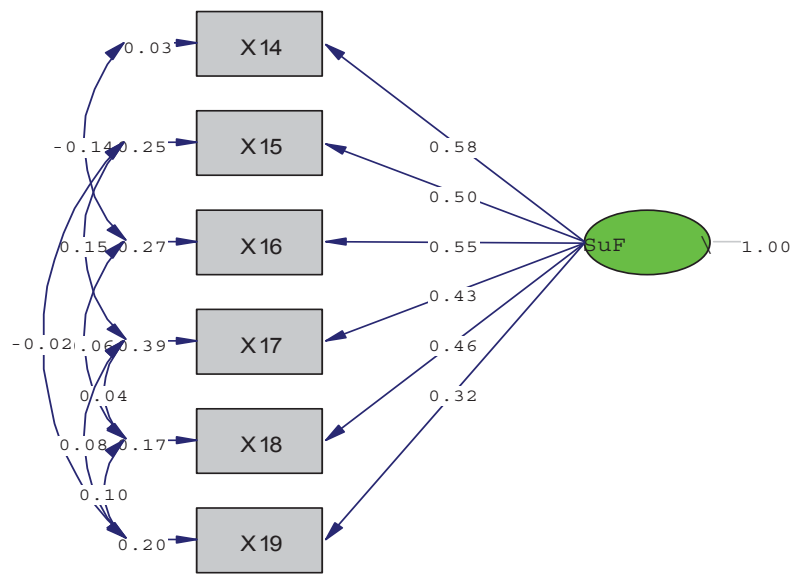

Chi-Square=0.99, $d f=2, P-v a l u e=0.60830, \quad$ RMSEA $=0.000$

Picture 4: Model of Confirmatory factors of Supportive Factor

Table 5. Results of Analysis of Confirmatory factors of Supportive Factor

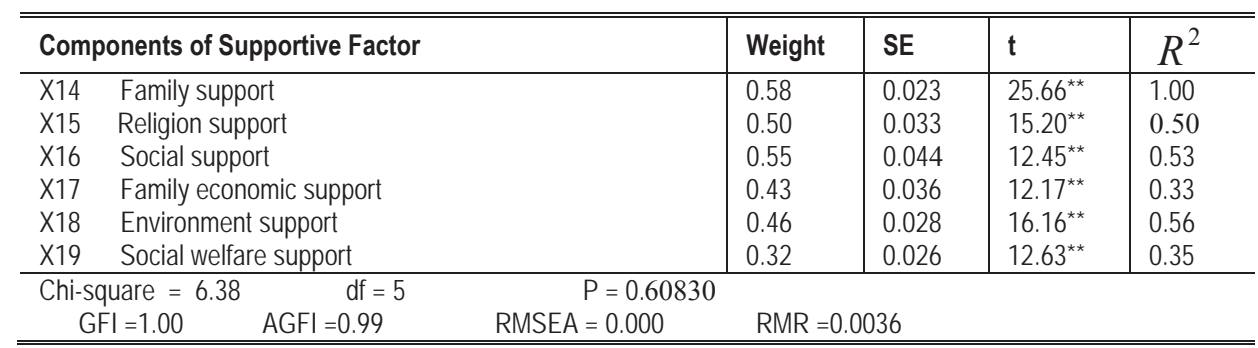

** Statistically significant level of 0.01

From picture 4 and table 5, results of analysis of confirmatory factors of SuF from 6 observed variables was revealed that the model was congruent to empirical data by considering from 1) Goodness of Fit Index (GFI) equaled to 1.00 and Adjust Goodness of Fit Index (AGFI) equaled to 0.99, 2) Root Mean Square Error of Approximation (RMSEA) equaled to 0.041 (RMSEA < 0.05) and 3) Chi- Square value had no statistically significant at level of .01 and divided by degree of freedom was lesser than or equaled to $5\left(\chi^{2} / \mathrm{df} \leq 5.00\right)$.

Considering on loading weight of 6 observed variables in model, it was revealed that observed variables had loading weight with 0.32 to 0.58 and had covariate to model of SuF with 33.00 to 100.00 percents.

\section{Confirmatory Factors Analysis of Endogenous Variables}

\subsection{Confirmatory Factors Analysis of Endogenous Variables of Inspiration of Public Mind (IPM)}

Confirmatory Factors Analysis of Endogenous Variables of Inspiration of Public Mind (IPM) affecting to Health Behavior $(\mathrm{HB})$ was revealed as the followings.

Confirmatory Factors of Inspiration of Public Consciousness for IPM had Bartlett's test of Sphericity of 858.792 statistically significant level $(p<0.01)$ and Kaiser-Mayer-Olkin Measure of Sampling Adequacy/MSA) of 0.774. This 
indicated that components of IPM aspect had proper relationship at good level and it can be used for analysis of confirmatory factors as shown in picture 5 and table 6 .

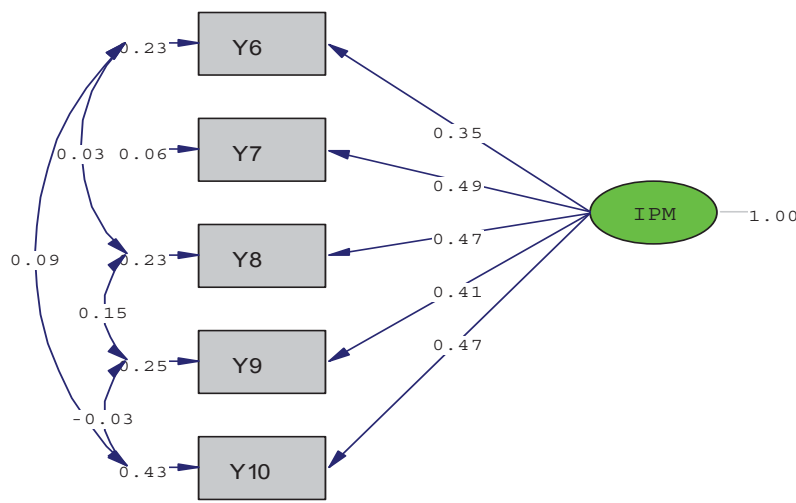

Chi-Square=0.01, $d f=1, P-v a l u e=0.93266, \quad R M S E A=0.000$

Picture 5: Model of Confirmatory factor of Inspiration of Public Mind

Table 6. Results of Analysis of Confirmatory factors of Inspiration of Public Mind

\begin{tabular}{|c|c|c|c|c|c|}
\hline Confirmatory factors of IPM & & Weight & SE & $\mathrm{t}$ & $R^{2}$ \\
\hline Y6 Person as role model & & 0.35 & 0.020 & $20.24^{\star \star}$ & 0.34 \\
\hline Y7 Impressive event & & 0.49 & 0.020 & $20.34^{\star *}$ & 0.80 \\
\hline Y8 Impressive environment & & 0.47 & 0.022 & $18.91^{\star *}$ & 0.49 \\
\hline Y9 Self-Public consciousness & & 0.41 & 0.025 & $17.12^{\star \star}$ & 0.39 \\
\hline Y10 Media receiving & & 0.47 & 0.041 & $7.25^{\star \star}$ & 0.34 \\
\hline Chi-square $=0.01 \quad \mathrm{df}=1$ & $P=0.93266$ & \multirow{2}{*}{\multicolumn{4}{|c|}{$\mathrm{RMR}=.00066$}} \\
\hline $\mathrm{GFI}=1.00 \quad \mathrm{AGFI}=1.00$ & RMSEA $=0.000$ & & & & \\
\hline
\end{tabular}

** Statistically significant level of 0.01

From picture 5 and table 6, results of analysis of confirmatory factors of IPM from 5 observed variables was revealed that the model was congruent to empirical data by considering from 1) Goodness of Fit Index (GFI) equaled to 1.00 and Adjust Goodness of Fit Index (AGFI) equaled to 1.00, 2) Root Mean Square Error of Approximation (RMSEA) equaled to 0.046 (RMSEA < 0.05), and 3) Chi- Square value had no statistically significant at level of .01 and divided by degree of freedom was lesser than or equaled to $5\left(\chi^{2} / \mathrm{df} \leq 5.00\right)$.

Considering on loading weight of 5 observed variables in model, it was revealed that observed variables had loading weight with 0.35 to 0.49 and had covariate to model of IPM with 34.00 to 80.00 percents.

\subsection{Confirmatory Factors Analysis of Endogenous Variables of Health Behavior (HB)}

Confirmatory Factors of Health Behavior (HB) had Bartlett's test of Sphericity of 2262.743 statistically significant level $(p<0.01)$ and Kaiser-Mayer-Olkin Measure of Sampling Adequacy/MSA) of 0.902. This indicated that components of HB aspect had proper relationship at good level and it can be used for analysis of confirmatory factors as shown in picture 6 and table 7 . 


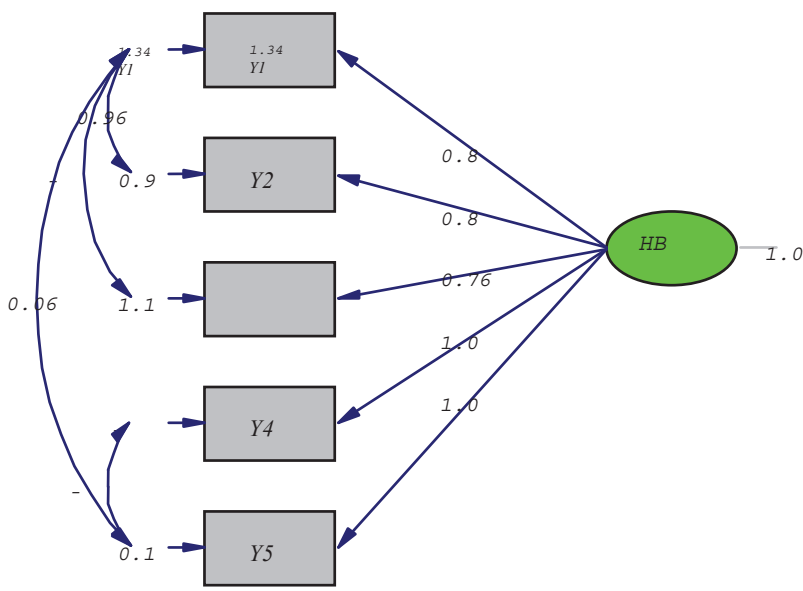

Chi-Square $=0.04, d f=1, \quad P$-value $=0.84600, \quad R M S E A=0.000$

Picture 6: Model of Confirmatory factors of Health Behavior

Table 7. Results of Analysis of Confirmatory factors of Health Behavior

\begin{tabular}{|c|c|c|c|c|c|c|c|}
\hline \multicolumn{4}{|c|}{ Confirmatory factors of Health Behavior } & Weight & SE & $\mathrm{t}$ & $R^{2}$ \\
\hline Y1 & \multicolumn{3}{|c|}{ Elderly self hygiene behavior } & 0.83 & 0.070 & 11.90 ** & 0.34 \\
\hline Y2 & \multicolumn{3}{|c|}{ Family behavior for elderly health care } & 0.84 & 0.064 & $13.05^{\star \star}$ & 0.44 \\
\hline Y3 & \multicolumn{3}{|c|}{ Community behavior for elderly health care } & 0.76 & 0.066 & $11.54^{\star \star}$ & 0.35 \\
\hline Y4 & \multicolumn{3}{|c|}{ Social behavior for elderly health care } & 1.00 & 0.062 & $23.34^{\star \star}$ & 0.99 \\
\hline Y5 & \multicolumn{3}{|c|}{ Elderly health risk behavior } & 1.00 & 0.062 & $16.36^{\star \star}$ & 0.87 \\
\hline \multicolumn{8}{|c|}{ Chi-square $=0.04 \quad \mathrm{df}=1 \quad \mathrm{P}=0.84600$} \\
\hline & $\mathrm{GFI}=1.00$ & $\mathrm{AGFI}=1.00$ & RMSEA $=0.000$ & \multicolumn{2}{|c|}{$\mathrm{RMR}=0.0023$} & & \\
\hline
\end{tabular}

** Statistically significant level of 0.01

From picture 6 and table 7, results of analysis of confirmatory factors of HB from 5 observed variables was revealed that the model was congruent to empirical data by considering from 1) Goodness of Fit Index (GFI) equaled to 1.00 and Adjust Goodness of Fit Index (AGFI) equaled to 1.00, 2) Root Mean Square Error of Approximation (RMSEA) equaled to 0.000 (RMSEA < 0.05) and 3) Chi- Square value had no statistically significant at level of 0.01 and divided by degree of freedom was lesser than or equaled to $5\left(\chi^{2} / \mathrm{df} \leq 5.00 \quad\right.$ ).

Considering on loading weight of 5 observed variables in model, it was revealed that observed variables had loading weight with 0.76 to 1.00 and had covariate to model of HB with 34.00 to 99.00 percents.

\section{Results of Effect among Variables in Model in Terms of Direct Effect and Indirect Effect}

1) Confirmatory factors of Elderly Health Care Knowledge (EHK) had direct effect to Inspiration of Public Mind (IPM) with no statistically significant at level of 0.05 with effect 0.08 and Health Behavior (HB) with statistically significant at level of 0.01 with effect 0.44 . Moreover, confirmatory factors in aspect of Elderly Health Care Knowledge (EHK) had indirect effect to Health Behavior (HB) with no statistically significant at level of 0.05 with effect of 0.03 .

2) Confirmatory factors of Psychological Trait (PsT) had direct effect to Inspiration of Public Mind (IPM) and and Health Behavior (HB) with statistically significant at level of 0.01 with effect 0.50 and 0.19 . Moreover, 
confirmatory factors in aspect of Psychological Trait (PsT) had indirect effect to Health Behavior (HB) with statistically significant at level of 0.01 with effect of 0.17 .

3) Confirmatory factors of Psychological State (PsS) had direct effect to Inspiration of Public Mind (IPM) and Health Behavior (HB)with statistically significant at level of 0.01 with effect 0.41 and 0.25 . Moreover, confirmatory factors in aspect of Psychological State (PsS) had indirect effect to Health Behavior (HB) with statistically significant at level of 0.01 with effect of 0.14 .

4) Confirmatory factors of Supportive Factor (SuF) had direct effect to Inspiration of Public Mind (IPM) and Health Behavior (HB) with statistically significant at level of 0.01 with effect of 0.34 and 0.34 . Moreover, confirmatory factors in aspect of Supportive Factor (SuF) had indirect effect to Health Behavior (HB) with statistically significant at level of 0.01 with effect of 0.12 .

5) Confirmatory factors of Inspiration of Public Mind (IPM) had direct effect to Health Behavior (HB) with statistically significant at level of 0.01 with effect of 0.34 .

6) Considering on structural model of confirmatory factors of Elderly Health Care Knowledge (EHK), Supportive Factor (SuF), Psychological State (PsS) and Psychological Trait (PsT) were able to explain the variation of endogenous factors of Inspiration of Public Mind (IPM) to caused Health Behavior (HB) with 86.00 percents as the following in equation (1).

$\mathrm{HB}=0.34^{*} \mathrm{PPM}+0.44^{*} \mathrm{EHK}+0.19^{*} \mathrm{PsT}+0.25^{*} \mathrm{PsS}+0.34^{*} \mathrm{SuF}$

$\mathrm{R}^{2}=0.86$

Equation (1) factors that had the most effect to Health Behavior (HB) was Elderly Health Care Knowledge (EHK), and subsequences were Inspiration of Public Mind (IPM), Supportive Factor (SuF), Psychological State (PsS) and Psychological Trait (PsT). These were able to explain the variation of Health Behavior (HB) with 86.00 percents.

Moreover, confirmatory factors of Elderly Health Care Knowledge (EHK), Supportive Factor (SuF), Psychological Trait (PsT) and Psychological State (PsS) were able to explain the variation of confirmatory factors of Inspiration of Public Mind (IPM) with 82.00 percents. Therefore, the equation can be written as the following in equation (2).

$\mathrm{IPM}=0.08^{\star} \mathrm{EHK}+0.50^{\star} \mathrm{PsT}+0.41^{\star} \mathrm{PsS}+0.34^{\star} \mathrm{SuF}$

$\mathrm{R}^{2}=0.82$

Equation (2) factors that had the most effect to Inspiration of Public Mind (IPM) was Psychological Trait (PsT), subsequences was Psychological State (PsS), Supportive Factor (SuF), and Elderly Health Care Knowledge (EHK), these were able to explain the variation of Inspiration of Public Mind (IPM) with 82.00 percents.

7) Considering on Chi-Square value/df was 1.609 , therefore it was lesser than 5, therefore it was accepted that hypothetical model of research was congruent to empirical data. Moreover, it was considered on other statistical values to identify the congruence that were RMSEA $=0.043(<0.05), \mathrm{GFI}=0.94, \mathrm{AGFI}=0.91$ (GFI, AGFI between 0.90-1.00), RMR=0.010 $(<0.05)$ and critical number $=227.20$ which is more than 200 . It indicated that model was congruent to empirical data. The results of analysis of causal relationship model and analysis of path effect as presented in picture 7 . 


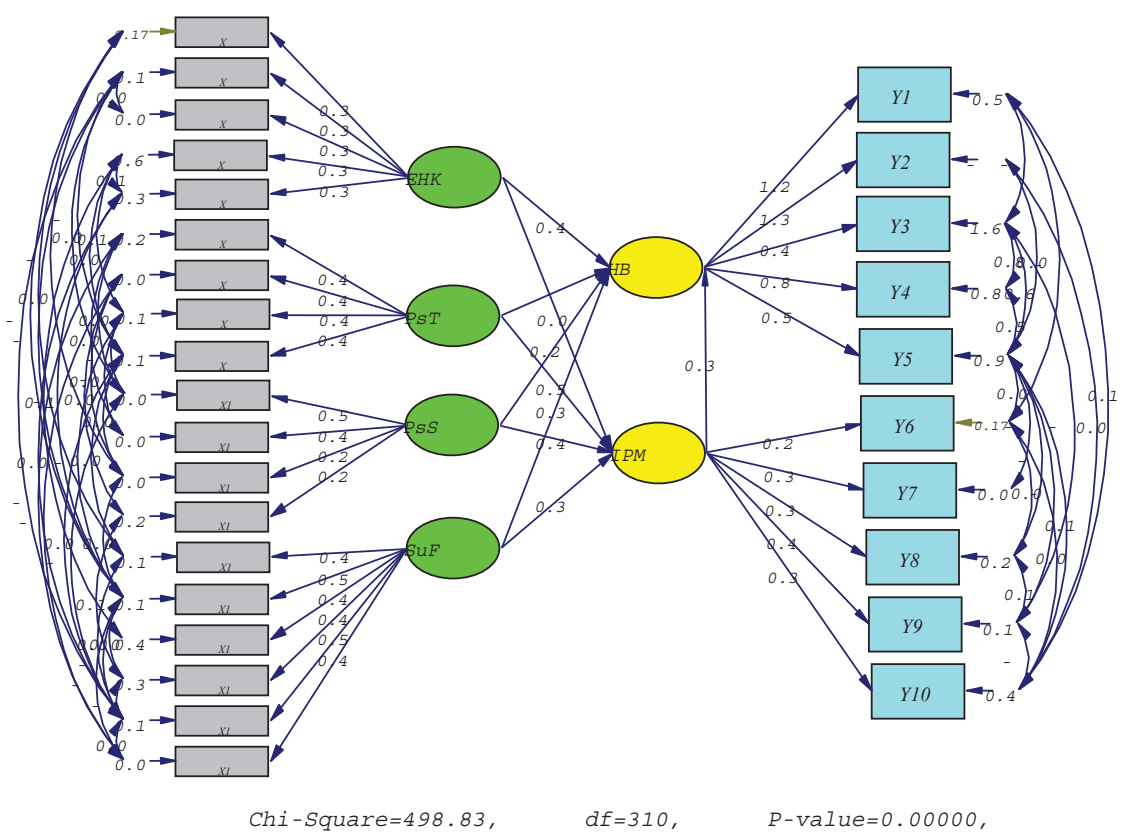

Picture 7: Causal Relationship Model of Elderly Health Care Behavior with Public Mind

\section{Discussion}

The findings indicated that Components of Elderly Health Care Knowledge (EHK) comprised of Elderly physical health knowledge (X1), Elderly mental health knowledge (X4), Elderly general disease knowledge (X2), Elderly specific health knowledge (X3) and Elderly health risk knowledge (X5) and can predict the Elderly Health Care Knowledge (EHK) with $0.44,0.43,0.32,0.32$ and 0.30 respectively. Its results were congruent to the study of Phinnarach, et al., 2012a, who studied on "Causal Relationship Model of Community Strength", revealed that health care knowledge had direct effect to community strength that composed of healthy self-care behavior, self-care behavior for family members, and self-care behavior for community peoples. This result is also pertinent to the study of Artwanichakul, et al., 2012a on "Structural Model of Dengue Fever Prevention and Control Behavior" found that dengue disease knowledge had directly effect to disease prevention and control behavior with 0.50. It might be concluded that that health care knowledge had direct effect to health behavior.

Component of Confirmatory factors of Psychological Trait (PsT) had direct effect to Inspiration of Public Mind (IPM) and Health Behavior (HB) with statistically significant at level of 0.01 with effect 0.50 and 0.19 . Moreover, confirmatory factors in aspect of Psychological Trait (PsT) had indirect effect to Health Behavior (HB) with statistically significant at level of 0.01 with effect of 0.17 . This indicated that Psychological Trait play important role for elderly health care behavior.

While considering on prediction of correlation of observed variables of Mercy and Kindness (X7), Locus of Control (X9), Self-confidence (X6), and Motive Achievement (X8), can predict the Psychological Trait (PsT) with 0.46, 0.46, 0.43, and 0.39 respectively. This result is congruent to the concept of psychologists about psychological trait also an important factor that affected to behavior of people in research of Thiengkamol that studied on the affecting of psychological trait to environmental behavior (Thiengkamol, 2012c; Thiengkamol, 2012d).

Simultaneously, Psychological State (PsS) had direct effect to Inspiration of Public Mind (IPM) and Health Behavior (HB) with statistically significant at level of 0.01 with effect 0.41 and 0.25 . Moreover, confirmatory factors in aspect of Psychological State (PsS) had indirect effect to Health Behavior (HB) with statistically significant at level of 0.01 with effect of 0.14 . While considering on prediction of correlation of observed variables of Self-value living (X10), Attitude toward Sufficiency (X11), Religion belie (X12), Family-value living (X13), and Religion Belief (X12) can predict 
the Psychological State (PsS) with $0.48,0.48,0.28$, and 0.27 respectively. This result is congruent to the concept of psychologists about psychological state also an important factor that affected to behavior of people in different researches of Thiengkamol and her colleagues, that studied on the affecting of psychological state to environmental behavior for global warming alleviation (Thiengkamol, 2011;; Thiengkamol, 2012c; Thiengkamol, 2012d; Thiengkamol, 2012e; Thiengkamol, 2012f; Donkonchum, \& Thiengkamol, 2012; Udornboon, et al., 2012b).

Components of Supportive Factor (SuF) comprised of Family support (X14), Social support (X16), Religion support (X15), Environment support (X18), Family economic support, and Social welfare support (X19), can predict the SuF with $0.58,0.55,0.50,0.46,0.43$ and 0.32 respectively. This were pertinent to various studies (Srithamrongsawat, et al., 2009; Yodpetch, S, 2009; Kespichayawattana, \& Jitapunkul, 2009; Knodel, \& Chayovan, 2008; Minkler, et al., 2008; Montgomery, \& Kwak, 2008; Nocon, \& Pearson, 2000; Neufeld, \& Harrison, 2010; O'Shea, 2002; Saunder, 2006; Toseland,et al., 2007) that the results illustrated that these supportive factors influencing to elderly health care behaviors.

Additionally, Confirmatory factors of Inspiration of Public Mind (IPM) had direct effect to Health Behavior (HB) with statistically significant at level of 0.01 with effect of 0.34 , even as considering on prediction of correlation of observed variables of Impressive event (Y7), Impressive environment (Y8), Media receiving (Y10), Self-public consciousness (Y9), and Person as Role Model (Y6), can predict the Inspiration of Inspiration of Public Mind (IPM) with 0.49, 0.47, 0.47, 0.41 and 0.35 respectively. These were congruent to different studies of Thiengkamol and her colleagues (Thiengkamol, 2011i; Thiengkamol, 2011j; Thiengkamol, 2012a; Thiengkamol, 2012b; Thiengkamol, 2012c; Donkonchum, et al, 2012a; Donkonchum \& Thiengkamol, 2012; Artwanichakul, et al., 2012a; Artwanichakul et al., 2012a; Gonggool, et al., 2012b; Jongwutiwet, et al., 2012a; Mongkonsin, et al., 2013b; Morrasri, et al., 2012b; Phinnarach, et al., 2012a; Pimdee, et al., 2012a; Ruboon, et al., 2012a; Tumpracha, et al., 2012b; Sangsan-anan, et al., 2012a; Udonboon et al., 2012b; Waewthaisong, et al., 2012a; Waewthaisong, et al., 2012b) that the results illustrated that Inspiration of Public Consciousness or public mind influencing to perform better health or environmental behaviors.

Therefore, the research results should be introduced to promote elderly health care behavior via self-health care and help other old person who is unable to help himself via public mind rising in family, community, social, religion organization, local administration organization and national level to corroborate with establishing systemic elderly health care network. This might lead to success of elderly heath quality.

Nevertheless, it might be concluded whether EHK, PsT, PSS, SuF, and IPM latent variables are essential component to cause the elderly people to adjust their health behaviors regarding to elderly self hygiene behavior, family behavior for elderly health care, community behavior for elderly health care, social behavior for elderly health care, elderly health risk behavior through IPM. Therefore, the model of EHK, PsT, PsS, and SuF influencing through IPM to $\mathrm{HB}$ was verified the proposed model was fitted with all observed variables according to criteria of Chi-Square value differs from zero with no statistical significant at 0.01 level or Chi-Square/df value with lesser or equal to 5, RMSEA (Root Mean Square Error Approximation) and RMR (Root Mean Square Residual) values with lesser than 0.05 including index level of model congruent value, GFI (Goodness of Fit Index) and index level of model congruent value, AGFI (Adjust Goodness of Fit Index) between 0.90-1.00.

\section{References}

Artwanichakul, K., Thiengkamol, N., \& Thiengkamol, T. (2012a). Structural Model of Dengue Fever Prevention and Control Behavior. European Journal of Social Sciences, 32 (4):485-497.

Cairns, R. B. (1979). Social Development. The origins and plasticity of interchanges. San Francisco : W.H. Freeman and Company.

Cervone, D. (1991). The two disciplines of personality psychologies. Review of Handbook of personality; Theory and research. Psychological Science, 2, 371-377.

Chamrasritwomg A. \& Chulert, P. (2009). Study for Surveillance "Role and Function Thai Family" in Transformation Situation of Social and Population. Social and Population, 2009, 28-47.

Chansirakanjana, S. (2009). Manual for Take Care Parents. (Second Edition).Bangkok: Aksornsampan Publishing.

Donkonchum, S. and Thiengkamol, N. (2012). Model of Environmental Education and Psychological State Affecting to Global Warming Alleviation. International Proceedings of Economic Development and Research, 44, 1-5.

Donkonchum, S. Thiengkamol, N., \& Thiengkamol, C. (2012a). Causal Relationship Model of Environmental Conservation Behavior Integrated with LCA Knowledge. European Journal of Social Sciences, 33 (1):5-13.

Ekwall, A. K., \& Hallberg, I. R. (2007). The association between caregiving satisfaction, difficulties and coping among older family caregivers. Journal of Clinical Nursing, 16, 832-844.

Gonggool, D., Thiengkamol, N., \& Thiengkamol, C. (2012b). Development of Environmental Education Volunteer Model through Inspiration of Public

Consciousness for Sustainable Development. European Journal of Social Sciences, 32 (1):150-160. 
Heaney, C. A., \& Israel, B. A. (1997). Social Networks and Social Support. In K. Glanz,

F. M. Lewis, \& B. K. Rimer. (Eds), Health behavior and Health education (pp. 179-205), California: Jossy-Bass Inc.

Hooyman, N. R. \& Kiyak, H. A. (2009). Social Gerontology A Multidisciplinary Perspective (8th ed.), Boston: Pearson.

Horner, B., \& Boldy, D. P. (2008). The benefit and burden of "ageing-in-place" in an aged care community. Australian Health Review, 32(2), 356-365

Kelly, K., Reinhard, S. C., \& Brooks-Danso, A. (2008). Executive Summary: Professional Partners Support Family Caregivers. AJN, 108(9), 6-12.

Kespichayawattana, J., \& Jitapunkul, S. (2009). Health and Health Care System for Older Persons. Ageing Int, 33, 28-49.

Koff, T. H. (1982). Long-Term Care An Approach to serving the Frail Elderly. Boston: Little, Brown and Company.

Knodel, J., \& Chayovan, N. (2008). Population ageing and the well-being of older persons in Thailand: Past trends, current situation and future challenges. Bangkok: UNFPA Thailand and Asia and the Pacific Regional Office.

Magnusson, D., and Endler, N.S. (1997). Interactional psychology and Personality. New York: John Whitey \& Sons.

Magnusson, D. (1999). Holistic interactionism : A perspective for research on personality development. In L.A. Pervin \& O.P. John (Eds.), Handbook of personality : Theory and research, pp. 219-247, New York : Guilford.

Magnusson D. (2001). The holistic-Interactionistic Paradigm : Some Directions for Empirical Developmental Research. European Psychologist, Vol. 6, No 3, pp. 153-162.

Maranet, N. (2012). Tendency of Increasing of Older People over the World and in Thailand. Retrieved on 12 Sep 2012 from: http://service.nso.go.th/nso/data/02/wld_pop47.html

Minkler, M., Hammel, J., Magasi, S., et al. (2008). Community-Based Participatory Research in Disability and Long-Term Care Policy A Case Study. Journal of Disability Policy Studies, 19(2), 114-126.

Montgomery, R., \& Kwak, J. (2008). TCARE: Tailored Caregiver Assessment and Referral. AJN, 108(9), 54-57.

Mongkonsin, Thiengkamol, N., \& Thiengkamol, T. (2013b). Causal Relationship Model of Flood Response Behavior. Mediterranean Journal of Social Sciences, 4 (1):587-598.

Morrasri, P., Thiengkamol, N., \& Thiengkamol, T. (2012b). Causal Relationship Model of Little Green Child with Environmental Behavior. European Journal of Social Sciences, 34 (2):177-189.

Neufeld, A., \& Harrison, M. (2010). Nursing and Family Caregiving Social Support and Nonsupport. New York: Springer Publishing Company.

Nocon, A., \& Pearson, M. (2000). The role of friends and neighbours in providing support for older people. Ageing and Society, $20,341-$ 367.

Office of National Statistic. (2012). World Population: Thai Population B.E. 2547. Retrieved on 10 Sep 2012 from: http://service.nso.go.th/nso/data/02/wld_pop47.html

O'Shea, E. (2002). Improving the quality of life of elderly persons in situations of dependency. The Council of Europe Publishing.

Pervin, L. A. (1999). Epilogue : Constancy and change in personality theory and research. In L.A. Pervin \& O.P. John (Eds.), Handbook of personality : Theory and research (pp. 689-704). New York : Guilford.

Pervin, L. A. (2001). A dynamic Systems Approach to Personality. European Psychologist. Vol. 6, No. 3, pp. 172-176.

Phinnarach, K., Thiengkamol, N., \& Thiengkamol, C. (2012a). Causal Relationship Model of Community Strength. European Journal of Social Sciences, 34 (3):379-392.

Phothisita, C. \& Tawesit, S. (2009). Social and Population B.E.2552in in Transformation Situation. Nakhonprathom: October Publishing.

Pimdee, P., Thiengkamol, N., \& Thiengkamol, T. (2012a). Causal Relationship Model of Electrical Energy Conservation. European Journal of Social Sciences, 32 (3):306-315.

Population Division, Department of Economic and Social Affairs (DESA), United Nations. (2001).World Population Ageing 1950-2050. New York: United Nations Publications.

Punthumnavin, D. (2008). Feature of Hypothesis and Data Analysis Providing for Utilization of Results of Development Research. Bangkok: National Research Council of Thailand (NRCT).

Ratanatikul, N., et al. (2012). World population. King Mongkut's University of Technology Thonburi Retrieved on 2 Oct 2012 from: http://cpe.kmutt.ac.th/wiki/index.php

Ruboon, O., Thiengkamol, N., Thiengkamol, T., \& Kurokodt, J. (2012a). Model of Environmental Education Teacher with Inspiration of Environmental Conservation for Global Warming Alleviation. European Journal of Social Sciences, 31 (1):92-102.

Saunder, P. (2006). The Role of State and Family in the Living Conditions of Older People in Urban China: Changing Attitudes and Outcomes. Social Policy \& Society, 5(3), 359-372.

Srithamrongsawat, S, Boonthancharoen, K., Sasat, S, \& Amnaksatsue, K. (2009). Model of Long Term Heath Care for Old People in Community. The Thai Journal of Primary Care and Family Medicine.23-31.

Thiengkamol, N. (2009a). The Great Philosopher: the Scientist only know but Intuitioner is Lord Buddha. Bangkok: Prachya Publication.

Thiengkamol, N. (2009b). The Happiness and the Genius can be Created before Born. Bangkok: Prachya Publication.

Thiengkamol, N. (2009c). Environment and Development Book 2 (Food Security). Bangkok: Chulalongkorn University Press.

Thiengkamol, N. (2011e). Environment and Development Book 1. (4th ed.). Bangkok: Chulalongkorn University Press.

Thiengkamol, N. (2011f). Nurture Children to be Doctors. Bangkok: INTELLUALS.

Thiengkamol, N. (2011i). Development of Model of Environmental Education and Inspiration of Public Consciousness Influencing to Global Warming Alleviation. European Journal of Social Sciences, 25 (4):506-514. 
Thiengkamol, .N. (2012a). Development of A Prototype of Environmental Education Volunteer. Journal of the Social Sciences, 7 (1):7781.

Thiengkamol, N. (2012b). Development of Food Security Management for Undergraduate Student Mahasarakham University. European Journal of Social Sciences, 27 (2):246-252.

Thiengkamol, N. (2012c). Model of Psychological Trait Affecting to Global Warming Alleviation European Journal of Social Sciences, 30 (3), 484-492.

Thiengkamol, N. (2012d). Model of Psychological Factors Affecting to Global Warming Alleviation. International Proceedings of Economic Development and Research, 44, 6-12.

Thiengkamol, N. (2012e). Causal Relationship Model of Environmental Education. Mediterranean Journal of Social Sciences, 3 (11), 1118.

Thiengkamol, N. (2012f). Causal Relationship Model of Environmental Education and Psychological Trait. Mediterranean Journal of Social Sciences, 3 (11), 263-272.

Thiengkamol, N. (2012h). Model of Environmental Education and Psychological Factors Affecting to Global Warming Alleviation. Mediterranean Journal of Social Sciences, 3 (11), 427-436.

Toseland, R. W., Naccarato, T., \& Wray, L. O. (2007). Telephone Groups for Older Persons and Family givers: Key Implementation and Process Issues. Clinical Gerontologists, 31(1), 59-76

Tumpracha, K., Thiengkamol, N., \& Thiengkamol, C. (2012b). Causal Relationship Model of Food Security Management. Mediterranean Journal of Social Sciences, 3 (11) : 639-650.

Udonboon, C. Thiengkamol, N., \& Thiengkamol, C. (2012b). Causal Relationship Model of Water Conservation Behavior. Mediterranean Journal of Social Sciences, 3 (11):591-604.

Waewthaisong, S. Thiengkamol, N., \& Thiengkamol, C. (2012a). Causal Relation Model of Environmental Traveling Behavior . European Journal of Social Sciences, 33 (1):184-195.

Wechwitan, P. (2008). Family Elderly Care in Thai Rural Family: From the Perception of Old person and Adult Child. Journal of Gerontology and Geriatrics (that I know of.), A journal of the Association of Gerontology and Geriatrics Thailand, 9(1), 25-3.

Yodpetch, S. (2009). Integrative System for Elderly Long Term Care. Bangkok: J Print Publishing.

Zuckerman, M. (1998). Psychobiological theories of personality. In D.F. Barone, M. Hersen, \& V.B. Hasselt (Eds), Advances in personality (pp. 123-154). New York : Plenum.

World Health Organization. (2012). The health are challenges posed by population ageing. Bulletin of the World Health Organization, 90 (2), February 2012, 77-156. 
